\title{
BRAIN. Broad Research in Artificial Intelligence and Neuroscience
}

ISSN: 2068-0473 | e-ISSN: 2067-3957

Covered in: PubMed.gov; IndexCopernicus; The Linguist List; Google Academic; Ulrichs; getClTED; Genamics JournalSeek; J-Gate; SHERPA/RoMEO; Dayang Journal System; Public Knowledge Project; BIUM; NewJour; ArticleReach Direct; Link+; CSB; CiteSeerX; Socolar; KVK; WorldCat; CrossRef; Ideas RePeC; Econpapers; Socionet.

2020, Volume 11, Issue 1, Sup.1, pages: 22-37 | https://doi.org/10.18662/brain/11.1Sup1/26

\section{Violence on Minors in Forensic Medicine}

Iuliana HUNEA ${ }^{1}$, Manuela CIOCOIU ${ }^{2}$, Nona GîRLESCU ${ }^{3}$, Diana BULGARU ILIESCU ${ }^{4}$

${ }^{1}$ The Institute of Forensic Medicine, 4, Buna Vestire Str., Iasi, Romania, Pathophysiology Department "Gr. T. Popa" University of Medicine and Pharmacy, 16, Universitatii Str., Iasi 700115, Tel.: +40 232267 801, Romania,

zamisnicu.iuliana@gmail.com

${ }^{2}$ Pathophysiology Department, "Gr. T. Popa" University of Medicine and Pharmacy, 16 Universitatii Str., Iasi 700115, Tel.: +40 232267 801, Romania, mciocoiu2003@yahoo.com

${ }^{3}$ The Institute of Forensic Medicine, Iasi, Romania; Department of Morphofunctional Sciences, "Gr. T. Popa" University of Medicine and Pharmacy, 16 Universitatii Str., Iasi 700115, Tel.: +40 232267 801, Romania,nona.girlescu@yahoo.com

${ }^{4}$ The Institute of Forensic Medicine, Iasi, Romania; Department of Forensic Medicine, "Gr. T. Popa" University of Medicine and Pharmacy, 16 Universitatii Str., Iasi 700115, Tel.: +40 232267 801, Romania, bulgarudiana@yahoo.com
Abstract: The offense of "ill-treatment of the minor" under Article 197 of the CPC (Civil Procedure Code) has in time been the subject of a nonunitary jurisdictional practice, which in 2009 led to the introduction of an appeal in the interest of the law. The type of offense in this case is impossible to prove without legal medicine and medicine in general because the court could not properly assess the "serious danger", the ill-treatment of the minor being both a criminal offense and a threat of crime. One of the equivalences in their medical practice is the Silverman Syndrome, which we will present along with a case of parental negligence, this time when the solution of acquittal or conviction lies in the conclusions of the forensic report, then in demonstrating the intention or praeterintentia as forms of guilt by perpetrators by the court.

Keywords: violence; minors; abuse; neglect.

How to cite: Hunea, I., Ciocoiu, M., Gîrlescu, N., \& Bulgaru Iliescu, D. (2020). Violence on Minors in Forensic Medicine. BRAIN. Broad Research in Artificial Intelligence and Neuroscience, 11(1Sup1), 22-37.

https://doi.org/10.18662/brain/11.1Sup1/26 


\section{Introduction}

Violence on the child captures a multitude of concepts (Nambo, 2019) for a wide range of forms of abuse (physical, verbal, emotional, sexual), ill-treatment, neglect and exploitation (economic/work, sexual), which also include phenomena such as abduction and/or disappearance, migration in risk situations, human trafficking. All this can be manifested in all the environments in which the child grows and develops (Sandu \& Ignătescu, 2020). This phenomenon can be subsumed to violence against oneself, interpersonal and collective violence. The classification in one category or another is made according to the particularity of the act and the relationship between the offender and the minor.

Abuse and neglect are the main forms of violence against minors, and they find their regulation in Law no. 272/2004 (Parliament of Romania, 2004) on the protection and advocacy of the rights of the child.

Child abuse is understood as "any voluntary action of a person who is in a relationship of responsibility, trust or authority towards him, by which life, physical, mental, spiritual, moral or social development, bodily integrity, the physical or mental health of the child are endangered".

Child neglect is understood as "the omission of a person who has the responsibility of raising, caring or educating the child to take any measure subordinated to this responsibility, which endangers life, physical, mental, spiritual, moral or social development, bodily integrity, physical or psychic health of the child." Neglect results in situations where the parents or persons in the care of the minor involuntarily fail to provide the care and education the child needs and thus endanger the physical, mental, spiritual, moral or social development, integrity physical, mental or physical health of the child. If the omission is voluntary, the abuse will be demonstrated. In other words, the difference between abuse (ill treatment applied to the minor) and negligence is realized by the subjective side of the act. Thus, the abuse has as guilt forms of the intention (direct, indirect) or praeterintent, while the fault enters the form of violence in the category of negligence. All these mark the difference between the act and the crime, that commits criminal liability through Art. 197 of The New Penal Code /NPC (Parliament of Romania, 2009).

\section{The Battered Child Syndrome}

In forensic medicine, forms of physical violence are reflected in The Battered Child Syndrome. The history of this syndrome begins in 1946 when 
John Caffey titled an article "Multiple Fractures in the Long Bones of Infants Suffering from Chronic Subdural Hematoma." (Caffey, 1946/2010).

Dr. Caffey describes in detail the history of 6 children under 1 year of age who had chronic subdural hematoma in association with multiple long bone fractures (total 23 fractures). But after eliminating all the probable pathologies, it did not establish the certain traumatic etiology of the lesions (Geddes et al., 2000).

It was not until 1962 that Kempe et al., in the article "The Battered Child Syndrome", managed to impose the unanimous recognition of this syndrome (Kempe et al., 1962). Silverman Syndrome (which recognizes injuries of violence anywhere on the body surface produced by any mechanism) is accepted as Shaken Baby Syndrome (SBS), which is a form of acute (or chronic) encephalopathy with hematoma or blade of subdural haemorrhage, retinal haemorrhage and other lesions produced in a unclear context in a child under 3 years (some authors mention 5 years; most commonly, 1 year) (Johnson et al., 2013).

The suspicion of this syndrome should be raised in practice (Kamberi, 2018) in the following cases: child brought to hospital with an acute (manifestation) lesion +/- other old or recent lesions (bruises, burns, fractures, malnutrition, dehydration, erythema fesier); or without evidence on the external examination, delay in presenting the child to the doctor, the marked discrepancy between the history provided by the parents (vague, contradictory) and the obvious signs with the tendency to (self) explain: "it makes easy bruises, it always falls, it is fastidious / has multiple allergy" (Johnson et al., 2013).

\section{Shaken Baby Syndrome}

From the epidemiological point of view, SBS predominates in children under 3 years, with the maximum incidence below 1 year, with a death rate of $10-40 \%$, and, in the survival cases, the incidence of sequelae is 93\% (behavioral, cognitive disorders, cerebral palsy, blindness, epilepsy). In $55 \%$ of cases, boys are the ones affected (probably due to the fact that in boys there is a faster increase in volume of the cranial cavity in relation to the content, thus the brain has more freedom of movement).

The portrait of the offender (Sandu, 2018) is characterized by under the age of 25 and male, having the quality of parent, friend of parents, babysitter.

Risk factors are: young parents, emotionally immature, unstable family situation (recent divorce), prematurity of the child, low socio- 
economic status, depressive situations (loss of work place, death in the family), birth of another child, family with a history of intra-familial abuse (Meytahler et al., 2001).

As aetiology of the syndrome, the following mechanisms are incriminated: by vigorous shaking of the child's chest, arms, shoulders or feet, repeated movements of flexion-extension are printed on the cephalic extremity, all the more pronounced in infants who do not have welldeveloped cervical musculature. It is a traumatic association without impact, produced by an indirect whiplash mechanism, with repeated accelerationsdecelerations and consecutive flexion-extension movements of the head. The most dangerous ones are the angular accelerations in the rotating component movements because there are unequal, asymmetrical slippages of the cerebral hemispheres relative to each other, relative to the walls of the skull, with an impact with both the walls of the brain and the brain itself. Also, the centrifugal force resulting from the rotational movement removes the hemispheres from each other, putting stress on the callus body and producing lesions at this level. However, there are also authors who do not recognize the veracity of this mechanism and who state that such injuries cannot be caused by the mere shaking of the body, in the absence of an impact between the head and a body/hard surface (cf. Experiment Duhaime on primates would require acceleration of $300 \mathrm{G}$ to induce injuries, or by shaking, forces of maximum 10G are developed) (Johnson et al., 2013; Smith et al., 2003).

Of course, there are patterns of injuries with an impact on the head, in these cases the lesions being somewhat specific to the classical mechanical traumatic mechanisms (adapted to the particularities of the infant's craniocerebral brain; e.g., rare contusions of the counter-stroke or extradural hematoma), but the specialized literature recognizes, in most cases, and supports, the existence of pure SBS, without impact.

Characteristic of SBS is the discrepancy between external (minor) and internal brain lesions (subdural hematomas, subarachnoid hemorrhage, cerebral contusions, cervical spinal cord injury, retinal hemorrhage, diffuse axonal injury).

Subdural hematoma is found in over $90 \%$ of cases. It is produced by the rupture of the cortico-dural veins, as a result of the antero-posterior shear by the flexion-extension movements imprinted on the head of the child. It can be uni- or bilateral with the tendency to expand in the interhemispheric ditch. In many cases the volume of the hematoma is not a substitute for space, in contrast to the serious clinical condition of the patient, which makes us believe that, in the SBS, the subdural hematoma 
would not cause death. In any case, it serves as an indicator of brain trauma. Occasionally, there have been cases of chronic HSD with re-bleeding, indicating repeated abuse as chronic HSD with risk of re-bleeding is encountered only in children with coagulopathy, cerebral atrophy or hydrocephalus. As well, subdural hematomas of different ages can coexist, attesting repeated traumas.

Retinal hemorrhages are present in $85-100 \%$ of cases, being represented by preretinal, intraretinal and retroretinal hemorrhages, often with a confluent character, less often than in vitreous hemorrhage $(10 \%)$; sometimes they are accompanied by detachment/rupture, infarction or optic nerve atrophy. In 81-85\% retinal lesions are bilateral (Knight, 1976). No link has been established between the localization of the retinal (right/left) hemorrhage with that of the subdural hematomas. To explain these injuries, several theories have been issued:

- hypertension in the retinal venous system (in the central vein of the retina) as a result of cerebral edema;

- vascular mechanism: transient stopping of blood flow due to compression of the carotid-ophthalmic vascular system during shaking of the head or through retinal vasospasm;

- direct mechanical mechanism: displacement of the vitreous $=>$ traction of the retina;

- vascular rupture due to the sliding of the retinal layers and their disruption;

- acute chest compression, with Valsalva effect and with retinal hemorrhages due to increased intracranial venous pressure (very rarely separated after cardio-respiratory resuscitation);

- the strong fractionation of the optic nerves by the brain sliding inside the cranial box, for this mechanism advocating the relatively frequent findings of retinal haemorrhages with a concentric character around the papilla of the optic nerve.

The cerebral contusion occurs very rarely and is caused by the morphological immaturity of the brain structures, with the lack of myelination; it occurs more frequently in the calyx body, in the basal faces of the frontal and temporal lobes (by contact with the rough surface of the base of the skull) and in the superior cerebellar peduncles (by striking the cerebellum tent), being usually accompanied by cerebral edema, which has moderate intensity (Adams et al., 1982).

Spinal cord injuries are subdural hematomas and high cervical spinal contusions explaining respiratory rate disorders. 
Diffuse axonal lesions (LADs) are reducible and typical lesions for SBS, probably involved more than the subdural hematoma in the unfortunate prognosis of the syndrome (Povlishock, 1992). These occur as a result of the rotating movements of the head, which creates shear forces, the technique of identifying these lesions being the immunolabeling for $68-\mathrm{kDa}$ neurofilament and for the precursor protein of beta amyloid (beta-APP), thus visualizing the axonal amputation bulbs, in the form of round or oval axonal retraction balls (Knight, 1976). A macroscopic indicator would be the vascular lesions that accompany the axonal ones that are seen as dots or fine hemorrhagic stripes (streak hemorrages) in the white substance; they are inconsistent in children due to the high elasticity of the vessels in this age category; the affected areas of choice are the bald body, the parasagittal white matter, the bridge, the cerebral aqueduct (Knight, 1976; Mimasaka et al., 2000). The LADs are probably more involved than the subdural hematoma in the unfortunate prognosis of the syndrome; affirmation supported by clinical evidence: in cases that showed no more than this lesion, the clinic was dominated by lethargy, unconsciousness, respiratory depression/apnea, seizures. During normal head movement, the tension developed in the axons is not harmful, in vitro studies showing that the axon has the capacity to extend up to $100 \%$ of its length, due to the viscoelasticity, without causing intraaxonal injury. The axonal injury is dependent on the magnitude and duration of the force (Mimasaka et al., 2000).

The physical properties of the brain, such as its mass and shape, are essential. The density differences between the gray and the white substances explain why LADs are formed at the limit by shear, tension and compression forces. The presence of the brain stem can be a barrier, which the brain hits, especially in the lateral movements, for which these movements are considered more likely to produce LADs than the posterior ones. Also, in the rotational movement, the cerebral hemispheres move away from each other, thus explaining the lesions from the level of the callous body (Johnson et al., 2013). The forces acting on the skull box are not fully understood but are common both in road accidents and in precipitation, through acceleration-deceleration mechanisms, and also in the so-called "baby shaken syndrome" (Mimasaka et al., 2000). Regarding the last pathological entity listed above, Joseph Shapiro has launched a new hypothesis regarding the thalatogenesis, claiming that death does not occur as a result of LAD production but as a result of nerve damage that irritates the diaphragm at the time of the extensive neck flexion, death being caused by respiratory failure. After trauma to the brain, two pathological forms appear in the injured axons. Initially called retraction bulbs, they were 
identified at the proximal end of the interrupted axon (Geddes et al., 2000). Later it was observed that these bulbs are formed by progressive axonal focal dilatation, which eventually leads to secondary axotomy, now called axonal bulbs or reactive axonal swelling. In other axons, these dilations have been observed not to evolve, taking the name of axonal varicosities. In humans, this swelling is visible from the first hour after trauma, appearing as dilations of $10-20 \mu \mathrm{m}$, which increase in size, reaching $24-48$ hours at $50 \mu \mathrm{m}$. During this time the sweeling can coexist with the retraction bulbs and with the progressive sweeling (Davis et al., 1984; Centerwall et al., 2000). It was found that in the most affected axons, disturbances of sodium homeostasis and intracellular calcium are observed, with the elevation of its levels producing progressive focal dissolutions at the system level of alpha2spectrine and ankyrin 3 subaxolemia and with the passive accumulation of water, which contributes to the progression of sweelling (Centerwall et al., 2000). With these, we note the mitochondrial impairment with the alteration of the cytoskeleton and including axonal transport, resulting in cellular debris that accumulates at the level of the swelling. This process leads to secondary or delayed axotomy, which disconnects the two axonal ends, forming the characteristic image of the LAD, namely the retraction bulbs, widely characterized by Povlishock (Povlishock, 1992), who initially claimed that mechanical forces act directly on the cytoskeleton and neurofilaments, with subsequent disruption of axonal transport. During this time, Adams and colab. were the ones who argued that the secondary axotomy is the result of focal alterations of the axolemy permeability, with the massive increase in the influx of Ca (Adams et al., 1982; Davis et al., 1984; Centerwall et al., 2000; Maxwell, 1996). Even if not even identified immunohistochemically, the presence of triple association (subdural haemorrhage, subarachnoid haemorrhage, retinal haemorrhages) should be the marker of LAD convulsions. Glasgow score (GCS) is one of the most important indicators of the severity of traumatic interest in brain function in SBS. The data on the average Glasgow score in patients with SBS at the time of presentation to the emergency department vary by author, most of them being in the range 9-12 GCS, with a correlation between GCS severity and prognosis (Centerwall et al., 2000; Maxwell, 1996).

Gillilanda has developed a definition of SBS based on clinical diagnostic criteria: equimotic marks of compression with the fingers and/or costal fractures; subdural and/or leptomeningeal hemorrhage; strong shake history (Strich, 1956). According to this researcher, at least two criteria met diagnose SBS. 
Paraclinical investigations are: eyeball, CT, MRI, Rx, laboratory blood tests (for differential diagnosis of hemorrhagic lesions), lumbar puncture.

The differential diagnosis is made by coagulation disorders, ocular hemorrhages during labor or as a result of resuscitation (although very rare occurrences are considered), other retinopathies, any other cause of subdural hematoma, including its production by direct cranial impact.

The prognosis is unfavorable: $19 \%$ of the victims die, $55 \%$ have neurological sequelae, $65 \%$ have visual sequelae disorders, while only $22 \%$ are completely cured. It seems that, except for the cases of cures without sequelae, the usual evolution of brain lesions is towards hypoxic ischemic encephalopathy, which is sometimes also cause of death.

At 6 months after trauma, the lesions are already stabilized, when the victims may have multicystic encephalomalacia, porencephaly, diffuse cortical atrophy, microglia, hydrocephalus or retinal detachment, optic nerve atrophy. (Strich, 1956).

In addition to the characteristic SBS lesions listed above, in a child with Silverman syndrome, lesions of ano-genital abuse, linear fractures of the parietal bones, tegument burned with cigarettes, signs of hot water immersion, old scars, traumatic alopecia (isolated, positioned), contagious wounds of the lips, dental expulsion, malnutrition, dehydration, weight loss, developmental delay, poor hygiene, costal fractures at different stages of healing, long bone fractures with spiral path (very suggestive in a child under 1 year that still does not walk, clearly caused by the twist of the member) can be identified. Extremity fractures are found in $77 \%$ of abused children. Epiphyseal-metaphyseal fractures are highly suggestive of abuse because the force required to produce them must be much greater than that encountered in accidental traumas at this age (generally by forced grasping and snatching of the forearm of the child) (Merten et al., 1983).

\section{Ill-treatment applied to the minore - case report}

In order to illustrate violence directed at minors, we will present a case from the forensic practice, which initially raised the suspicion of illtreatment applied to the minor, attracting in the alternative to request further forensic expertise.

We will propose the case of the so-called A.I., age 1 year and 4 months, from the rural area, on whose behalf a traumatological expertise was ordered to be performed. 
The minor was admitted for 9 days with the diagnosis of "Unspecified degeneration of the lower limb".

The history of the disease records that the above is addressed urgently for edema in the lower limbs. He is hospitalized for clinicalbiological and specialized imaging behavior.

The pediatric surgery examination includes: hypotonia, psychomotor retardation, small skull (-2 DS), weight hypotrophy (G.-2.92 DS; T-0.760 DS), craniofacial dysmorphism, hypopigmented skin.

From the pediatric consultation we note: the child has signs and symptoms that may suggest phenylketonuria.

At the inspection of the lower limbs, there is edema, redness at the level of the bilateral limb, and at the level of the right leg there are yellowwhite spots. Sensitivity and peripheral pulse are present.

The pediatric examination records that there are clinical signs and symptoms that may suggest phenylketonuric pathology.

From the neurological consultation, the cranial perimeter of $43 \mathrm{~cm}$ and mild psychomotor retardation are retained.

Psychological consultation records delays in psychic and language development, psychomotor agitation.

$\mathrm{X}$-ray of the fist revealed a bone age corresponding to the chronological age of 10 months. The metaphyses of the forearm bones have a regular outline.

It is discharged with the diagnoses "Degeneration of the foot, grade I, bilateral; Acute tracheobronchitis; Iron deficiency anemia; Delay in psychosomatic and language development; Psychosomatic agitation; Slight psychomotor delay; Observation of phenylketonuria (under investigation)".

At the impartia forensic examination performed two months after the discharge, the absence of traumatic injuries is noted on the date of examination, a weight of $9 \mathrm{~kg}$, a waist of $72 \mathrm{~cm}$.

While the first-degree frostbite of the lower limbs are reversible lesions, without the potential for themselves to affect further development (characterized by local erythema and edema), the same cannot be said about the diagnoses of "Delay in psychic development and language; Slight psychomotor delay". At the same time, it should not be omitted that the frosts are the result of exposure to cold, a physical factor that acts both locally (the production of frosts - by rapid exposure - pediatric consultation "at the inspection of the lower limbs edema, redness at the level of the bilateral limb, and at the level of the right foot is observed yellow-white spots. Sensitivity and peripheral pulse present "and of the acute pernio by slow exposure over a long time at low temperatures $4-6{ }^{\circ} \mathrm{C}$ ), as well as in 
general, with severe thermoregulation disorders (all the more stressed in children and the elderly), exposure that sustained and prolonged can lead to hypothermia, with the death of the victim.

To form, the frostibite requires a stage of exposure to the cold with zonal vasoconstriction, a period of heating, with vasodilation and increased local blood flow. Depending on the extent of these vascular changes, different severity results from the first degree - the easiest, to the fourth degree - the most severe, with necrosis of the entire affected segment. The first degree frostbite present in the case of the minor are erythema-edematous, with the red, hot and swollen skin, all of which are reversible changes.

Regarding the diagnoses of "Delay in psychic development and language; Slight psychomotor delay, hypotrophy, at the pediatric examination, the clinical picture composed of hypotonia, psychomotor retardation, small skull (-2 DS), weight hypotrophy (G.-2.92 DS; T 0.760 DS), craniofacial dysmorphism, hypopigmented skin, it seems to be that of a phenylketonuria, an aspect also recorded in the observation sheet. Phenylketonuria is an autosomal recessive genetic disorder that affects the metabolism of phenylananine, by the enzymatic deficiency of phenylananinhydroxylase. In patients with phenylketonuria, it is not possible to convert phenylalanine into tyrosine; phenylalanine accumulates in the blood while the tyrosine concentration decreases, resulting in melanin deficiency, which explains the hypopigmentation of the skin. Excess phenylalanine in the blood is toxic to the nervous system and disrupts the development of the child's brain, with repercussions on the development of the intellect. Some of the excess phenylalanine reaches the systemic level, where the white matter affects the white matter by neuronal demyelination, and another part is converted into phenyl ketones and excreted in the urine.

In Romania, the screening test for phenylketonuria is performed routinely in maternity hospitals. Given that this was a home childbirth, with subsequent travel to maternity, the mpother could not say whether the test was performed. Subsequently, it was confirmed that the test was performed and the results did not require further diagnostic investigations, with phenylketonuria (phenylanaine $0.43 \mathrm{mg} / \mathrm{dl}$ in the first determination and $0.48 \mathrm{mg} / \mathrm{dl}$ in the second determination) being denied.

Weight hypotrophy recorded in the pediatric examination (G.-2.92 DS; T.-0.76 DS) correlated with psychomotor retardation, deficient anemia and bone age on left wrist $\mathrm{x}$-ray of 10 months, lead to deprivation nutrition, as an etiological factor incriminated.

Normal growth is defined by progression in weight and height consistent with established standards for age and sex, related to individual 
genetic potential and to hormonal, environmental, socio-economic and cultural factors. Waist, weight and speed of growth are currently the parameters unanimously accepted by the World Health Organization as markers of health status. The auxologic evaluation remains the method of choice in the early detection of growth and development disorders (Chitescu et al., 2018).

These parameters are compared with those of other healthy children, of the same age, sex and from the same geographical area graphically represented by a standardized Gaussian curve the World Health Organization (WHO, 1995) (Chart 1).

\section{Chart 1}

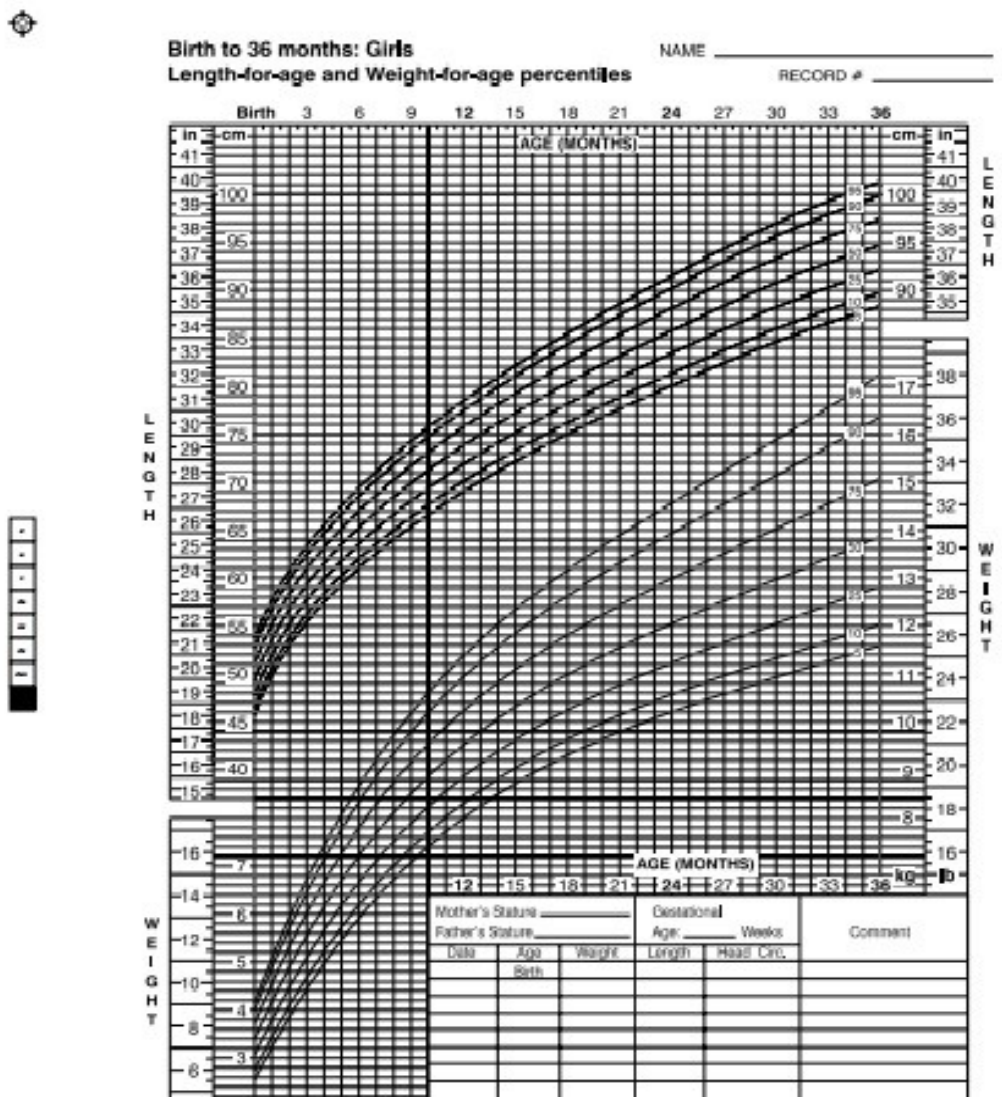

Of the reference values, the average is at the tip of the curve, and the deviations are expressed by the percentile or standard deviation (DS) 
method, with an accepted deviation from the ideal values of +2 DS (Diaconu et al., 2013).

For a quicker interpretation, in pediatric practice, the chart proposed by WHO has been transposed into values shown in the table below. The number of standard deviations for each parameter is calculated using the formula:

\section{$\underline{\text { DS }=\text { Real Parameter }- \text { Ideal Parameter for Age }}$}

Table 1

$$
\text { DS tabular (Table 1) }
$$

\begin{tabular}{|l|l|l|l|l|}
\hline $\begin{array}{l}\text { Age } \\
\text { (months) }\end{array}$ & Waist & SD waist & Weight & SD weight \\
\hline 14 & 74.8 & 2.6 & 9.71 & 0.79 \\
\hline 15 & 75.9 & 2.7 & 9.92 & 0.80 \\
\hline 16 & 77 & 2.7 & 10.15 & 0.81 \\
\hline 17 & 78 & 2.8 & 10.38 & 0.82 \\
\hline 18 & 79 & 2.9 & 10.56 & 0.84 \\
\hline 19 & 79.9 & 2.9 & 10.74 & 0.85 \\
\hline 20 & 80.8 & 3.0 & 10.91 & 0.87 \\
\hline 21 & 81.7 & 3.0 & 11.04 & 0.88 \\
\hline 22 & 82.8 & 3.0 & 11.25 & 0.89 \\
\hline 23 & 83.5 & 3.1 & 11.42 & 0.90 \\
\hline 24 & 84.2 & 3.1 & 11.58 & 0.91 \\
\hline
\end{tabular}

The forensic examination performed showed that the 1 year and four months (16 months) child weighed $9 \mathrm{~kg}$ and had a waist of $72 \mathrm{~cm}$. By applying the above formula, the following DS values for waist and weight are obtained:

$$
\begin{aligned}
& \text { SD weight }=\frac{9-10,15}{0,81}=-1,41 \mathrm{DS} \\
& \text { SD waist }=\frac{72-77}{2,7}=-1,85 \mathrm{DS}
\end{aligned}
$$

The obtained values fall within the accepted deviations, of +2 DS, from which it results that the weight deficit present at the hospitalization (G.-2.92 DS) has been recovered. In contrast, the DS for the waist, although still within the accepted parameters, increased. The correction of the weight deficit, after the period of hospitalization and the emergency placement in a social institution, is still a factor that supports the etiology by the deficit of 
contribution of the weight hypotrophy, resulting in the fact that the changes were reversible (Chart 2).

\section{Chart 2}

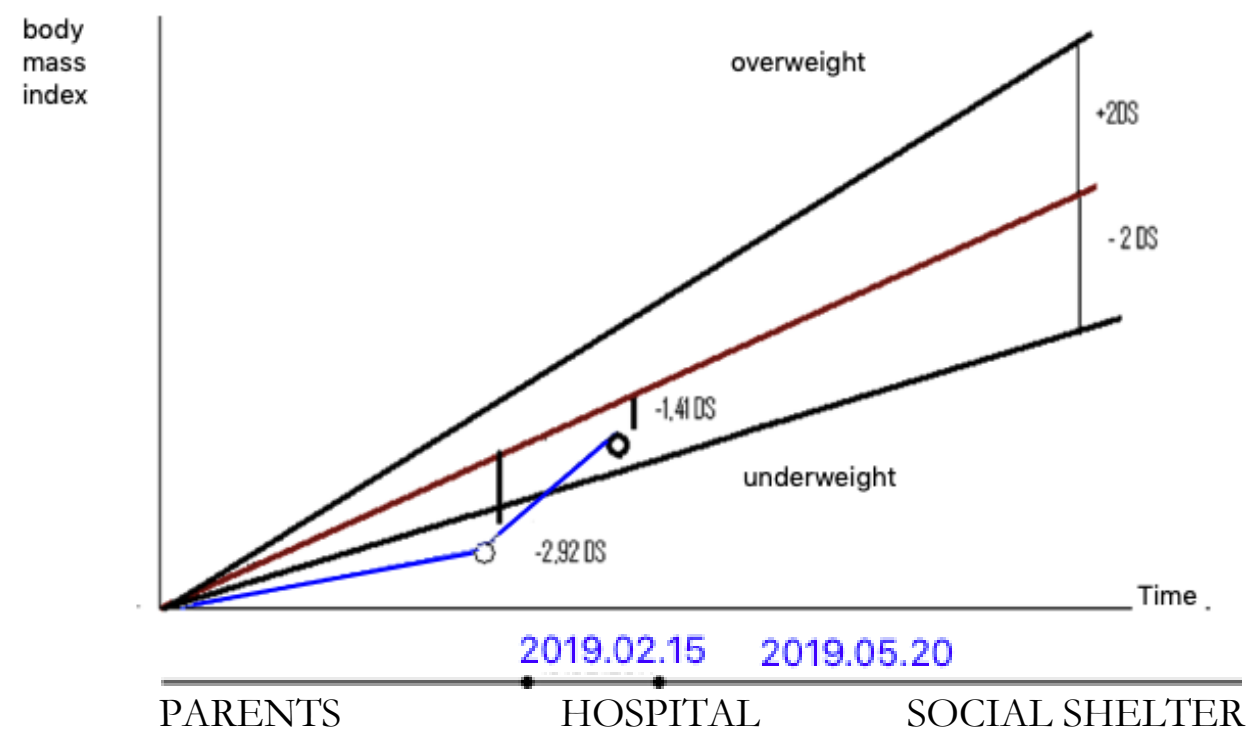

Nutrition particularly influences height-weight development. Thus, overfeeding leads to a height-weight advance with the conclusion of the increase in higher height, while malnutrition causes height-weight delay and neurological disorders, elements found in the case in question.

Another factor that influences somatic growth is the affectiveeducational environment in which the child develops. A balanced environment with the presence of both parents leads to a harmonious development, while a disharmonious family environment leads to a growth delay. This aspect is verified in the case in question because, although the weight deficit was corrected during the placement of the minor, DS of the waist, still in normal parameters, increased, moving away from the median.

The model of the height-weight growth has variations in time, so the evaluation is done by reference to the stage of development of the child and to the age.

The growth is divided into four periods:

1: prenatal

2: first years

3: 4 years - the beginning of puberty 


\section{4: pubertal}

The deficit present at admission in the case in question is in the second period of growth, in which the child grows up without specific hormonal influences. Hormonal deficits may go unnoticed during this period because no marked growth disorders occur. In contrast, deficits in these early years may cause a slowdown in growth (Table 2).

\section{Table 2}

\begin{tabular}{|c|c|}
\hline Endocrine causes & Other causes \\
\hline $\begin{array}{l}\text { - Permanent STH deficiency } \\
\text { (idiopathic, genetic, congenital, } \\
\text { acquired) } \\
\text { - Transient STH deficiency } \\
\text { (prepubertal, hypothyroidism) } \\
\text { - Excess glucocorticoids (Cushing's } \\
\text { syndrome) } \\
\text { - Pseudohipoparatiroidism } \\
\text { - Diabetes } \\
\text { - Untreated diabetes insipidus }\end{array}$ & $\begin{array}{l}\text { - Genetic growth delay } \\
\text { - Constitutional growth delay } \\
\text { - Intrauterine growth retardation (Russell } \\
\text { - Silver, embryo-fetopathies: } \\
\text { toxoplasmosis, rubella) } \\
\text { - Genetic diseases (Turner, Prader - Willi, } \\
\text { Lawrence - Moon) } \\
\text { - Chronic diseases: cardiovascular } \\
\text { (congenital heart disease with left - right } \\
\text { shunt, congestive heart failure); } \\
\text { pulmonary (bronchial asthma, cystic } \\
\text { fibrosis); gastrointestinal (celiac disease, } \\
\text { Crohn's disease); hematological } \\
\text { (thalassemia, siclemia); renal (chronic } \\
\text { uremia, renal tubular acidosis); } \\
\text { immunological (rheumatoid arthritis } \\
\text { juvenile); neurological (cranial tumors); } \\
\text { - Malnutrition (anorexia, post- } \\
\text { chemotherapy anorexia, psycho-affective } \\
\text { deprivation) }\end{array}$ \\
\hline
\end{tabular}

\section{Conclusions}

The lesions and pathologies present seem to show serious negligence, which of course must be proved by the investigation of the competent bodies.

Without substituting us for the magistrates, we believe that, if this had been proven, the case would have been classified by the prosecutor or paid by the court because the offense under Art. 197 of the NPC bears only on the intention and the pretense as guilt. 


\section{References}

Adams, J. H., Graham, D. I., Murray, L. S., \& Scott, G. (1982). Difuse axonal injury due to nonmissile head injury in humans: an analysis of 45 cases. Annals of Neurology, 12(6), 557-563. https://doi.org/10.1002/ana.410120610

Caffey, J. (2010). Multiple fractures in the long bones of infants suffering from chronic subdural hematoma. Clinical Orthopaedics and Related Research, 469(3), 755-758. https://doi.org/10.1007/s11999-010-1666-0 (Original paper published 1946).

Centerwall, S. A., Centerwall, W. R. (2000). The discovery of phenylketonuria: The story of a young couple, two retarded children, and a scientist. Pediatrics,105(1), 89-103. https://doi.org/10.1542/peds.105.1.89

Chitescu, C. L., Radu, A. D., Aciu, F., \& Moraru, M. (2018). New psychoactive substances (NPSs) abuse in Romania: Analytical strategies for drug screening in biological samples using high resolution mass spectrometry. Romanian Journal of Legal Medicine, 26(2), 173-182.

Davis, J. H., Rao, V. J., \& Valdes-Dapena, M. (1984). A forensic science approach to a starved child. Journal of Forensic Sciences, 29(2), 663-669. Retrieved from https://www.ncbi.nlm.nih.gov/pubmed/6233391

Diaconu, D., Cirdeiu, E., Anton-Păduraru, D. T., Trandafir, L. M., Oltean, C., Burlacu, M., \& Grigore, I. (2013). Pediatrie: Suport de lucrări practice pentru studenții Facultății de Medicină (pp. 25-32). Editura «Gr.T.Popa» UMF Iaşi.

Geddes, J. F., Whitwell, H. L., \& Graham, D. I. (2000). Traumatic axonal injury: practical issues for diagnosis in medicolegal cases, Neuropathology and Applied Neurobiology, 26(2), 105-116. https://doi.org/10.1046/j.13652990.2000.026002105.x

Johnson, V. E., Stewart, W., \& Smith, D. H. (2013). Axonal pathology in traumatic brain injury. Experimental Neurology, 246, 35-42. https://doi.org/10.1016/i.expneurol.2012.01.013

Kamberi, F. (2019). Knowledge and Attitudes of Nurses toward the Use of Nursing Diagnosis in Clinical Practice. Eastern-European Journal of Medical Humanities and Bioethics, 2(2), 43-55. http://dx.doi.org/10.18662/eejmhb/14

Kempe, C. H., Silverman, F. N., Steele, B. F., Droegemueller, W., \& Silver, H. K. (1962). The battered-child syndrome. The Journal of the American Medical Association(JAMA), 181(1), 17.

https://doi.org/10.1001/jama.1962.03050270019004

Knight, B. (1976). Forensic problems in practice. XI. Injury from physical agents. Practitioner, 217(1301), 813-18. Retrieved from https://www.ncbi.nlm.nih.gov/pubmed/995837 
Maxwell, W. L. (1996). Histopathological canges in central nodals of Ranvier after strech injury. Microscopy Research and Technique, 34(6), 522-535. Retrieved from https://www.ncbi.nlm.nih.gov/pubmed/8842021

Merten, D. F., Radkowski, M. A., \& Leonidas, J. C. (1983). The abused child: A radiological reappraisal. Radiology, 146(2), 377-381. https://doi.org/10.1148/radiology.146.2.6849085

Meythaler, J. M., Peduzzi, J. D., Eleftheriou, E., \& Novack, T. A. (2001). Current concepts: Diffuse axonal injury-associated traumatic brain injury. Archives of Physical Medicine and Rehabilitation, 82(10), 1461-1471.

https://doi.org/10.1053/apmr.2001.25137

Mimasaka, S., Funayama, M., Adachi, N., Nata, M., \& Morita, M. (2000). A fatal case of infantile scurvy. International Journal of Legal Medicine, 144(1-2), 122124. https://doi.org/10.1007/s004140000150

Nambo, J. (2019). Learning from violence: Middle-school principals facing school violence prevention programs. Revista Romaneasca pentru Educatie Multidimensionala, 11(3), 163-179. http://dx.doi.org/10.18662/rrem/163

Parliament of Romania. (2004). Law No. 272/2004 on the Protection and Promotion of the Rights of the Child. Romanian Official Gazette, Part I, 557. [Rom.]

Parliament of Romania. (2009). The New Penal Code. Art. 197. Retrieved from https://lege5.ro/Gratuit/gezdmnrzgi/codul-penal-din2009?pid=41994642\#p-41994642 [Rom.]

Povlishock, J. T. (1992). Traumatically induced axonal injury: Pathogenesis and pathobiological implications. Brain Pathology, 2(1), 1-12. Retrieved from https://www.ncbi.nlm.nih.gov/pubmed/1341941

Sandu, A., \& Ignătescu, C. (2020). Social Construction of the Legal System. Research in the Northeastern Region of Romania. Postmodern Openings, 11(1), 111-148. http://dx.doi.org/10.18662/po/111

Sandu, A. (2019). The social construction of probation counselor: Comparative qualitative analysis in Romania and the Republic of Moldova. Logos Universality Mentality Education Novelty: Social Sciences, 7(2), 72-99. http://dx.doi.org/10.18662/lumenss/10

Smith, D. H., Meaney, D., \& Shull, W. H. (2003). Diffuse axonal injury in head trauma. Journal of Head Trauma Rehabilitation, 18(4), 307-316. https://doi.org/10.1097/00001199-200307000-00003

Strich, S. J. (1956). Diffuse degeneration of the cerebral white matter in severe dementia following head injury. Journal of Neurology, Neurosurgery \& Psychiatry, 19(3), 163-185. https://doi.org/10.1136/innp.19.3.163

World Health Organization. (1995). Physical status: The use and interpretation of anthropometry. Technical Report Series No. 854, 121-311. Retrieved from https://www.who.int/childgrowth/publications/physical status/en/ 